\title{
Modulation of shark prey capture kinematics in response to sensory deprivation
}

Jayne M. Gardiner ${ }^{\mathrm{a}, \mathrm{b},{ }^{*}}$, Jelle Atema ${ }^{\mathrm{c}}$, Robert E. Hueter ${ }^{\mathrm{b}}$, Philip J. Motta ${ }^{\mathrm{a}}$

${ }^{a}$ University of South Florida, Department of Integrative Biology, 4202 E. Fowler Ave, Tampa, FL 33620, USA

${ }^{b}$ Mote Marine Laboratory, Center for Shark Research, 1600 Ken Thompson Parkway, Sarasota, FL 34236, USA

${ }^{c}$ Boston University Marine Program, 5 Cummington Mall, Boston, MA 02215, USA

* Corresponding author. Present address: New College of Florida, Division of Natural Sciences, 5800 Bayshore Rd, Sarasota, FL 34243, USA. Tel.: +1 941487 4456; fax: +1 9414874396.

E-mail address: jgardiner@ncf.edu (J.M. Gardiner). 


\begin{abstract}
The ability of predators to modulate prey capture in response to the size, location, and behavior of prey is critical to successful feeding on a variety of prey types. Modulating in response to changes in sensory information may be critical to successful foraging in a variety of environments. Three shark species with different feeding morphologies and behaviors were filmed using high-speed videography while capturing live prey: the ram-feeding blacktip shark, the ram-biting bonnethead, and the suction-feeding nurse shark. Sharks were examined intact and after sensory information was blocked (olfaction, vision, mechanoreception, and electroreception, alone and in combination), to elucidate the contribution of the senses to the kinematics of prey capture. In response to sensory deprivation, the blacktip shark demonstrated the greatest amount of modulation, followed by the nurse shark. In the absence of olfaction, blacktip sharks open the jaws slowly, suggestive of less motivation. Without lateral line cues, blacktip sharks capture prey from greater horizontal angles using increased ram. When visual cues are absent, blacktip sharks elevate the head earlier and to a greater degree, allowing them to overcome imprecise position of the prey relative to the mouth, and capture prey using decreased ram, while suction remains unchanged. When visual cues are absent, nurse sharks open the mouth wider, extend the labial cartilages further, and increase suction while simultaneously decreasing ram. Unlike some bony fish, neither species switches feeding modalities (i.e. from ram to suction or vice versa). Bonnetheads failed to open the mouth when electrosensory cues were blocked, but otherwise little to no modulation was found in this species. These results suggest that prey capture may be less plastic in elasmobranchs than in bony fishes, possibly due to anatomical differences, and that the ability to modulate feeding kinematics in response to available sensory information varies by species, rather than by feeding modality.
\end{abstract}


Keywords: Electroreception; Feeding behavior; Lateral line; Olfaction; Vision 


\section{Introduction}

Performance, or the ability to perform a task, is the link between an organism's phenotype and its ecology and behavior (Arnold, 1983). As a fitness-related behavior, performance during feeding is of the utmost importance. For animals to exploit a variety of prey types under a variety of conditions, feeding behavior must be plastic. The term "modulation" was originally proposed by Liem (1978) to describe the ability of a species to change its neuromuscular and kinematic patterns in order to produce discrete sets of prey capture behaviors in response to different feeding situations. This does not simply reflect intra-individual variation, but rather control of the animal's muscle activity patterns and behavioral repertoire, resulting in consistent, distinct transitions between behaviors as a direct response to a particular stimulus (Wainwright and Lauder, 1986; Ferry-Graham, 1997; Nemeth, 1997a). Differences in the ability to modulate ("modular multiplicity", Liem, 1978) among fishes have been linked to differences in the breadth of the diet and in feeding performance and fitness (Liem, 1980; Norton, 1991a, 1995; Nemeth, 1997a; Maie et al., 2014).

Among bony fishes, modulation has generally been considered to occur in response to different prey types, locations, sizes, shapes, textures, and degrees of elusivity (Nyberg, 1971; Elshoud-Oldendave and Osse, 1976; Liem, 1978, 1979, 1980; Lauder, 1981, 1983; Wainwright and Lauder, 1986; Wainwright, 1988; Norton, 1991a, 1995; Norton and Brainerd, 1993; Frost and Sanford, 1999; Van Wassenbergh et al., 2006; O'Neill and Gibb, 2014). The behavior, and therefore motor pattern chosen, is believed to depend on information gathered prior to the initiation of the strike (Liem, 1979). Since the predator must rely on sensory information to perceive the nature and location of the prey, modulation could also occur as a result of differences in how the predator senses the prey, for example when one or more sensory systems 
are not functional (Gardiner and Motta, 2012). It is currently unclear how sharks modulate their feeding behavior in response to changes in the available sensory information.

Sharks capture their prey by ram, suction, biting, or a combination of these behaviors. Ram feeding relies on the speed of the predator's strike (movement of the body towards the prey, often using a C-start or S-start) to overtake and engulf the prey (Liem, 1980; Norton, 1991b; Norton and Brainerd, 1993; Ferry-Graham and Lauder, 2001; Higham et al., 2005, 2006; Motta and Huber, 2012) and therefore generally requires that the predator localize and orient to the prey from a distance, to have sufficient room to accelerate for a rapid strike (Gardiner and Motta, 2012). Suction feeding, on the other hand, relies on a slow approach, followed by rapid expansion of the oral cavity to draw in the prey, and is only effective over a distance of about one mouth diameter (Weihs, 1980; Lauder and Clark, 1984; Motta et al., 2002; Day et al., 2005; Higham et al., 2006; Lowry and Motta, 2007; Nauwelaerts et al., 2007; Motta et al., 2008; Wilga and Sanford, 2008), so suction feeders may not need to localize their prey from as great a distance as a ram feeder. Since different sensory cues are available over different spatial scales (reviewed in Gardiner et al., 2014), changes in the sensory information available to detect and locate the prey can result in modulation. For example, the largemouth bass, Micropterus salmoides, normally relies on vision to perform its well-described ram-feeding behavior. When feeding in the dark, it localizes the prey using short-range lateral line cues and subsequently modulates towards more suction-based capture (Gardiner and Motta, 2012).

Among elasmobranchs, a few studies have found evidence for modulation of prey capture in response to prey size (Frazzetta and Prange, 1987; Wilga, 1997; Ferry-Graham, 1998a), but most species examined to date do not appear to modulate their feeding behavior based on the size, location, or elusivity of the prey (Ferry-Graham, 1997, 1998a,b; Wilga, 1997; Pretlow- 
Edmonds, 1999; Ajemian and Sanford, 2007). There appears to be a particular lack of modulation among species specialized for suction capture, even based on the presence or absence of food (Wu, 1993; Fouts and Nelson, 1999; Matott et al., 2002, 2005; Robinson and Motta, 2002). It has been suggested that ram-feeders should be capable of greater modulation than suction feeders because of the extremely short duration of the strike necessary for suction feeding, presumably restricting time for sensory feedback, and because the modal action pattern of ram feeding shows greater variability (Frazzetta and Prange, 1987; Ferry-Graham, 1997, 1998a; Pretlow-Edmonds, 1999; Motta and Wilga, 2001; Motta et al., 2002, 2008; Robinson and Motta, 2002; Matott et al., 2005; Ajemian and Sanford, 2007; Lowry and Motta, 2007), but contradictory evidence has also been presented for elasmobranchs (Wilga and Motta, 2000; Edmonds et al., 2001) as well as bony fishes (Aerts, 1990; Van Wassenbergh et al., 2006).

Recently, it was demonstrated that sharks from a variety of ecological niches, including both ram and suction feeders, are capable of using multiple sensory cues to detect, track, and locate prey, and can switch to alternate sensory cues when their preferred signals are unavailable (Gardiner et al., 2014). The goals of the present study were to examine the effects of the use of different sensory signals on the kinematics of prey capture in three species of sharks that differ in habitat use, diet, and feeding behavior, and to compare the ability to modulate their feeding behavior and kinematics based on different sensory cues. The blacktip shark, Carcharhinus limbatus, is a fast-swimming coastal shark that can be found in both clear and turbid waters. It feeds diurnally, ram-capturing highly elusive prey such as bony fish and elasmobranchs, both on the bottom and in the water column (Frazzetta and Prange, 1987; Castro, 1996). This species can initially detect the presence of prey using olfaction or vision. It uses vision to execute very rapid strikes from a distance of a few body lengths (BL), but can also strike from a closer proximity 
using the lateral line. Blacktip sharks cannot strike when vision and the lateral line are simultaneously blocked. Electroreception or touch can prompt the start of capture (Gardiner et al., 2014). The bonnethead, Sphyrna tiburo, is an epibenthic species found over seagrass beds and muddy bottoms, in clear to turbid waters. It feeds diurnally, using ram-biting almost exclusively, in some cases scooping up swimming crustaceans from seagrass beds but will also chase and capture crustaceans in the water column (Cortés et al., 1996; Wilga and Motta, 2000; Bethea et al., 2007). This species can also initially detect prey using olfaction or vision but it relies on vision to strike from a distance of about one body length, and it cannot strike in the dark. It requires electroreception to initiate mouth opening and subsequent capture (Gardiner et al., 2014). The nurse shark, Ginglymostoma cirratum, is a benthic species that inhabits coral reefs and rocky areas. It feeds nocturnally, using suction to capture fish, mollusks and crustaceans (Castro, 2000; Motta et al., 2002, 2008). This species requires olfaction to initially detect prey and strikes from close proximity using vision, the lateral line, or electroreception. Electroreception or touch can prompt the start of capture (Gardiner et al., 2014).

\section{Materials and methods}

\subsection{Experimental animals}

The experimental animals, behavioral procedures, and sensory deprivation techniques are described in detail in a previous paper (Gardiner et al., 2014) and are only briefly explained here. Eighteen young-of-the-year (YOY) blacktip sharks, C. limbatus, 51-65 cm total length (TL), were collected from Terra Ceia Bay, FL using rod and reel and gillnet gear. Ten juvenile nurse sharks, G. cirratum, 67-94 cm TL, were collected from waters near Long Key, FL using rod and reel gear. Sixteen bonnetheads, S. tiburo, 69-95 cm TL, were collected from Terra Ceia Bay, FL, 
and waters near Sarasota, FL using gillnet gear. Animals were held at Mote Marine Laboratory in Sarasota, FL in a 210,000 1 oval tank operated on a closed recirculating life support system with sand filtration and heater/chiller units, maintained at $24-26{ }^{\circ} \mathrm{C}$ on a $12 \mathrm{~h}: 12 \mathrm{~h}$ light:dark cycle. Animals were fed fish, shrimp, and squid, supplemented with Mazuri Vita-Zu Sharks/Rays vitamin supplement tablets (PMI Nutrition International, St. Louis, MO, USA), to satiation three

times per week, except during periods of experimentation, when food was withheld for $48 \mathrm{~h}$ prior to behavioral trials to ensure that the animals were motivated to feed. All animals were allowed to acclimate to captivity for at least 2-3 weeks prior to the initiation of any experiments. Experiments were conducted over the course of several months. Protocols for animal handling and use were approved by the Institutional Animal Care and Use Committees at the University of South Florida (W3817) and Mote Marine Laboratory (11-03-RH1).

\subsection{Behavioral procedures}

Experiments were conducted in a near-laminar flow channel, $7.5 \mathrm{~m}$ long x $2 \mathrm{~m}$ wide, 120 $\mathrm{cm}$ deep, with a flow rate of $2.3 \mathrm{~cm} / \mathrm{s}$. An individual shark was introduced into the channel, allowed to acclimate for $30 \mathrm{~min}$, then offered a piece of cut fish to confirm that it was hungry. If an animal did not consume the food, the trial did not proceed. The animal was then herded into a holding area ( $4 \mathrm{~m} \times 2 \mathrm{~m}$, behind a mesh gate) downstream of the test channel. A live prey item (nurse and blacktip sharks: pinfish, Lagodon rhomboides; bonnetheads: pink shrimp, Farfantepenaeus duorarum) was tethered at the upstream end of the flume to restrict it to the field of view of a high-speed camera (Photron FASTCAM-X 1024 PCI Model 100K; Photron USA Inc., San Diego, CA, USA), which recorded a lateral view of prey capture at 250 frames/s, through a window in the tank wall. Prey were tethered at different depths for the different 
species, according to their feeding habits. Pinfish were tethered midwater $(60 \mathrm{~cm}$ above the bottom) for the blacktip sharks and just off the bottom $(10 \mathrm{~cm})$ for the nurse sharks, while shrimp were tethered near the bottom $(30 \mathrm{~cm})$ for the bonnetheads. The experimental animal was held for 6 min to allow a turbulent prey odor plume establish, then the shark was released and a trial proceeded until the prey was captured or until $10 \mathrm{~min}$ had elapsed. During all trials, only the facility's overhead lights were used. Animals were tested with all senses intact (control) and with each of the sensory systems blocked (as outlined in Section 2.3), alone and in combination.

\subsection{Sensory deprivation}

Olfaction was blocked by inserting pieces of cotton soaked in petroleum jelly into the animal's nares. Vision was blocked by covering the eyes with pieces of heavy black plastic, attached to the skin around the margin of the eyes using cyanoacrylate glue. Because of differences in scale morphology among the species, two different methods were used to block the electrosensory system: the pores of the ampullae of Lorenzini were covered with cyanoacrylate glue (nurse and blacktip sharks) or silicone rubber paint (bonnetheads). Neither the glue nor the paint impeded the animals from opening and closing their mouths. All sensory blocks were applied while the animal was under anesthesia with tricaine methanesulphonate (MS-222) and animals were revived, then allowed to recover for $3 \mathrm{~h}$ prior to being moved into the experimental test channel. The lateral line system was lesioned by holding the animals in a $0.5 \mathrm{~g} / \mathrm{l}$ solution of streptomycin sulfate in seawater for $3 \mathrm{~h}$. For combinations of sensory blocks, those requiring anesthesia were applied first, then the streptomycin treatment was applied during the anesthesia recovery period. Acceptance of a piece of food after the blocking procedure was 
evidence that the anesthesia and blocking procedures themselves did not result in altered behavior (see Gardiner et al., 2014 for details).

\subsection{Video analysis}

Videos of prey strikes and captures were digitized using MaxTRAQ Lite+ v.2.2.2.2 software (Innovision Systems Inc., Columbiaville, MI, USA). Any feeding sequences in which the prey attempted to escape were excluded from analysis. Only those trials in which capture occurred laterally to the camera were used for analysis of capture kinematics. Multiple trials for each individual animal were pooled to form a mean for each animal under each treatment condition. Capture in all species was considered to begin with the start of lower jaw depression $\left(t_{0}\right)$ and end when the prey was engulfed (the center of mass of the prey passed the anterior margin of the mouth; $t_{\text {capture }}$, as per Gardiner and Motta (2012). Several kinematic events, which characterize the different phases of prey capture, were examined. Not all of the kinematic events measured were applicable to all species. For clarity, the species examined are indicated in brackets (blacktip shark $=\mathrm{BT}$, bonnethead $=\mathrm{BH}$, nurse shark $=\mathrm{NS}$ ) after each variable described below. The time (in ms) of the following kinematic events was calculated from video images (relative to $t_{0}$, as in Wilga and Motta, 1998, 2000): time of peak lower jaw depression; start of lower jaw elevation; time of complete jaw closure; start of cranial elevation (BT); time of peak cranial elevation (BT); start of cranial depression (BT); end of cranial depression (BT); start of upper jaw protrusion $(\mathrm{BT}$ and $\mathrm{BH})$; time of peak upper jaw protrusion $(\mathrm{BT}$ and $\mathrm{BH})$; end of upper jaw retraction (BT and $\mathrm{BH}$ ); start of labial extension (NS); time of peak labial extension (NS); end of labial retraction (NS). The following durations were calculated from the kinematic events above: time to peak gape; duration of peak gape; time to close jaws; total bite time (from 
$t_{0}$ to jaw closure); time to maximum jaw protrusion; duration of maximum jaw protrusion; time to retract upper jaw. Peak gape, maximum upper jaw protrusion (BT and BH), and maximum labial extension (NS) were calculated by digitizing the anterior tips of the upper and lower jaw and the anterior margin of the medial labial cartilage. During capture ( $t_{0}$ to $t_{\text {capture }}$, as in Gardiner and Motta, 2012), the positions of the predator and prey were digitized and used to calculate (in $\mathrm{cm}$ ) the predator-prey distance at the start of capture, ram distance, and suction distance, and (in degrees) the capture angle (measured from the corner of the mouth to the midpoint between the anterior end of the upper and lower jaws to the center of mass of the prey). These variables were used to calculate predator velocity during capture $(\mathrm{cm} / \mathrm{s})$, prey velocity during capture $(\mathrm{cm} / \mathrm{s})$, and the ram-suction index $(\mathrm{RSI})$, given by: $\mathrm{RSI}=\left(D_{\text {predator }}-D_{\text {prey }}\right) /\left(D_{\text {predator }}+D_{\text {prey }}\right)$. This index varies from +1 , a pure ram strike, to -1 , a pure suction strike (Norton and Brainerd, 1993).

Cranial elevation was not assessed in the nurse shark or bonnethead. Because of the position of the prey above the bottom and the relatively stationary position of the shark at the start of the strike, the nurse sharks' strike consisted of lifting the head (Fouts and Nelson, 1999), and thus cranial elevation during capture could not be distinguished from striking. Bonnetheads only elevate the head slightly during capture (Wilga and Motta, 2000). The bonnetheads in the present study struck at the prey from below, and thus this slight cranial head elevation, if present, was difficult to distinguish. Upper jaw protrusion during capture was not assessed in the nurse shark as it was frequently obscured by the extension of the labial cartilages (Motta et al., 2008).

\subsection{Statistical analysis}

Data for each species were regressed against total length using the ordinary least squares method to remove the effects of size (Packard and Boardman, 1999), and the standardized 
residuals were used in all subsequent analyses. All data were tested for normality and equality of variance with Kolmogorov-Smirnov tests and Levene's median tests (Sokal and Rohlf, 1995), respectively. In an effort to reduce the number of animals taken from the wild, individual animals were used in more than one, but not all, treatment groups, resulting in an unbalanced design. Data for the different treatments were therefore compared within each species using linear mixed models. Where significant differences were found, Tukey post hoc tests were then used to perform pairwise comparisons among the treatments. The Benjamini-Hochberg method was used to control the false discovery rate in multiple statistical tests (Benjamini and Hochberg, 1995). Analyses were conducted using R (version 3.0.2; R Core Team, 2013), nlme (version 3.1111; Pinheiro et al., 2013), and multcomp (version 1.3-1; Hothorn et al., 2008)).

\section{Results}

Data for all treatments are summarized in Tables S1-S3 in the supplementary online Appendix.

In the blacktip sharks, capture occurred in the control treatment (no senses blocked) and in the olfaction-, vision-, lateral line-, lateral line + olfaction-, and electroreception-blocked treatments only. In the control blacktip sharks, capture (the onset of lower jaw depression) began at a distance of $5.6 \pm 0.3 \mathrm{~cm}$ from the prey and an angle of $8.7 \pm 0.6^{\circ}$ (above or below the horizontal) to the prey, with respect to the midline of the jaws. When vision was blocked, animals began capture at a similar distance to the prey, but at a greater angle above or below the horizontal $\left(36.3 \pm 7.5^{\circ}, p<0.001\right)$. When the electrosensory system was blocked, captures began at a closer proximity $(3.5 \pm 0.5 \mathrm{~cm}, p=0.007)$ and greater angle $\left(27.7 \pm 7.8^{\circ}, p=0.001\right)$ to the prey. When the lateral line was blocked, alone or in combination with olfaction, capture began at 
a similar distance to that of the control treatment, but at a greater angle to the prey (lateral line: $14.1 \pm 2.1^{\circ}, p=0.04$; lateral line + olfaction: $\left.22.1 \pm 6.3, p=0.005\right)$.

In the bonnethead, captures occurred in the control, olfaction-, lateral line-, and lateral line + olfaction-blocked treatments only. Capture did not occur when the electrosensory system was blocked. Capture began from a distance of $4.7 \pm 0.2 \mathrm{~cm}$ and an angle of $14.2 \pm 3.3^{\circ}$ above or below the horizontal (control), which did not vary significantly among the treatments.

In the nurse shark, captures occurred in the control, vision-, lateral line-, lateral line + vision-, and electroreception-blocked treatments. Capture began at a distance of $4.0 \pm 0.3 \mathrm{~cm}$ and an angle of $31.9 \pm 3.6^{\circ}$ to the prey (control), which did not vary significantly among the treatments.

\subsection{Kinematic pattern}

In the control blacktip sharks, capture began with nearly synchronous lower jaw depression and cranial elevation. Upper jaw protrusion began as peak gape was reached, then the lower jaw began to elevate. The upper jaw reached maximum protrusion as the jaws closed. Prey was engulfed (i.e., the center of mass went past the teeth into the oral cavity) as the jaws began to close (Fig. 1). In the control bonnetheads, capture began with lower jaw depression, which reached a maximum prior to the start of upper jaw protrusion. The upper jaw began to protrude as the lower jaw began to elevate. Peak protrusion was maintained while the jaws closed and the upper jaw was retracted after the gape had closed. Engulfment occurred as the jaws were closing on the prey (Fig. 1). In the control nurse sharks, capture began with lower jaw depression, followed by the start of extension of the labial cartilages. Peak gape was reached as the labial cartilages reached peak extension, then the lower jaw began to elevate, followed by the start of 
labial cartilage retraction. The labial cartilages reached full retraction before the jaws closed. Prey was engulfed just after peak gape (Fig. 1). For all three species, the order of events was generally similar in the other treatments; however, there were differences in the onset and/or duration of the different events, or the magnitude of displacement, as outlined in Sections 3.23.5.

\subsection{Cranial elevation and lower jaw depression}

In the control blacktip sharks, cranial elevation began almost simultaneously with jaw depression, reaching a maximum displacement of $8.5 \pm 0.8^{\circ}$ after $47.1 \pm 4.2 \mathrm{~ms}$. When vision was blocked, cranial elevation began before the onset of lower jaw depression $(-2.9 \pm 17.4 \mathrm{~ms}, p$ $<0.001)$, reaching a greater angle, $15.3 \pm 3.4^{\circ}(p=0.008)$, over a longer time, $104.9 \pm 21.8 \mathrm{~ms}$ $(p<0.001)$. When the electrosensory system was blocked, cranial elevation also began before the onset of lower jaw depression $(-64.3 \pm 84.4 \mathrm{~ms})$; however, there was a large amount of variation among the animals in this treatment group and these differences were not significant (Fig. 1). When the lateral line + olfactory systems were blocked, the timing of the onset of cranial elevation and the maximum angle were not significantly different from the control; however, the time to maximum elevation was longer, $103.1 \pm 24.6 \mathrm{~ms}(p=0.009)$. The kinematics of cranial elevation were not significantly affected by the olfactory or lateral line blocks alone. The kinematics of cranial depression were not evaluated because the blacktip sharks tended to turn away from the camera at the end of capture, prior to complete cranial depression. As noted above (see Section 2.4), cranial elevation was not assessed for the nurse sharks and bonnetheads. 


\subsection{Gape cycle}

In the control blacktip sharks, the jaws reached their maximum gape, $5.4 \pm 0.3 \mathrm{~cm}$, in $69.3 \pm 5.7$ ms, which was maintained for $4.3 \pm 0.3 \mathrm{~ms}$. Lower jaw elevation lasted $43.9 \pm 3.8 \mathrm{~ms}$, resulting in a total bite time of $116.5 \pm 8.6 \mathrm{~ms}$. When olfaction or lateral line + olfaction were blocked, the time to peak gape was longer, $107.3 \pm 8.5 \mathrm{~ms}(p=0.02)$ and $113.5 \pm 15.7 \mathrm{~ms}(p=0.03)$, respectively. Time to peak gape was not significantly different among the other treatments. The magnitude of the maximum gape, duration of peak gape, time to close, and total bite time were not significantly different among any of the treatments (Fig. 2).

In the control bonnetheads, peak gape, $4.2 \pm 0.2 \mathrm{~cm}$, was reached in $113.9 \pm 5.9 \mathrm{~ms}$ and maintained for $12.9 \pm 2.0 \mathrm{~ms}$. Lower jaw elevation occurred over $93.7 \pm 4.6 \mathrm{~ms}$, resulting in a total bite time of $220.5 \pm 9.0 \mathrm{~ms}$. There were no significant differences in the magnitude of peak gape, time to peak gape, duration of peak gape, time to close, or total bite time among any of the treatments (Fig. 2).

In the control nurse sharks, the jaws reached their peak gape, $3.2 \pm 0.2 \mathrm{~cm}$, in $47.3 \pm 8.3$ $\mathrm{ms}$, which was maintained for $14.4 \pm 6.7 \mathrm{~ms}$. Lower jaw elevation occurred over $56.4 \pm 6.4 \mathrm{~ms}$, resulting in a total bite time of $121.2 \pm 16.1 \mathrm{~ms}$. When vision or the lateral line were blocked, the magnitude of peak gape was larger (vision block: $4.0 \pm 0.1 \mathrm{~cm}, p=0.002$; lateral line block: 3.9 $\pm 0.2 \mathrm{~cm}, p=0.02)$, but none of the other differences in the kinematics of the gape cycle among any of the treatments were statistically significant (Fig. 2).

\subsection{Upper jaw protrusion and labial cartilage extension}

In the control blacktip sharks, upper jaw protrusion began at $60.0 \pm 5.0 \mathrm{~ms}$, at approximately the same time as the jaws reached peak gape. The upper jaw protruded to a maximum displacement 
of $1.8 \pm 0.2 \mathrm{~cm}$ over $53.7 \pm 3.7 \mathrm{~ms}$. When the olfactory or lateral line + olfactory systems were blocked, upper jaw protrusion began significantly later, at $98.6 \pm 9.2 \mathrm{~ms}(p=0.008)$ and $103.7 \pm$ $16.5 \mathrm{~ms}(p=0.02)$, respectively, but still in synchrony with peak gape, which was reached later in these treatments (see Section 3.3, Figs. 1 and 2). The time to maximum jaw protrusion and jaw protrusion distance were not significantly different among any of the treatments. Jaw retraction was not assessed because the blacktip sharks tended to turn away from the camera prior to complete retraction.

In the bonnethead, upper jaw protrusion began after peak gape had been reached and as the jaws were closing, at $138.7 \pm 12.0 \mathrm{~ms}$. The upper jaw reached its maximum displacement, 0.9 $\pm 0.3 \mathrm{~cm}$, in $61.4 \pm 5.1 \mathrm{~ms}$, which was maintained for $26.0 \pm 3.6 \mathrm{~ms}$, followed by upper jaw retraction for $103.7 \pm 17.9 \mathrm{~ms}$ (Fig. 1). There were no significant differences in the kinematics of jaw protrusion among any of the treatments.

In the nurse shark, the labial cartilages began to extend $21.2 \pm 8.9 \mathrm{~ms}$ after the start of jaw depression, and reached their maximum extension, $2.1 \pm 0.2 \mathrm{~cm}$, over $31.9 \pm 3.6 \mathrm{~ms}$. The labial cartilages remained at their peak extension for $24.9 \pm 3.7 \mathrm{~ms}$ and then retracted over $27.7 \pm 3.7$ ms (Fig. 1). When vision or the lateral line were blocked, alone or in combination, the labial cartilages were extended significantly further (vision block: $2.8 \pm 0.1 \mathrm{~cm}, p=0.002$; lateral line block: $2.9 \pm 0.1, p=0.007$; lateral line + vision block: $2.8 \pm 0.2, p=0.03)$. When the electrosensory system was blocked, the labial cartilages were retracted significantly more slowly $(46.0 \pm 4.3 \mathrm{~ms}, p<0.001)$. There were no significant differences in the start of labial extension, time to maximum extension or duration of maximum extension among any of the treatments.

\subsection{Prey capture and the ram-suction index}


In the control blacktip sharks, the ram-suction index (RSI) value was $0.8 \pm 0.0$, indicative of a predominantly ram capture. Blocking the visual system resulted in a significantly lower RSI value, $0.6 \pm 0.1(p<0.001)$, though still predominantly ram capture. The RSI values did not differ significantly among the other treatments (Fig. 3). When broken down into the distances moved by the predator and the prey, the suction distance (distance moved by the prey) was not significantly different among any of the treatments. The ram distance (distance moved by the predator), however, was smaller when either the visual or electrosensory system was blocked, compared with when the olfactory or lateral line system were blocked (vision block: $5.8 \pm 1.0$ $\mathrm{cm}$, olfactory block: $8.6 \pm 0.6 \mathrm{~cm}, p=0.02$; lateral line block: $9.2 \pm 0.3 \mathrm{~cm}, p=0.02$; electrosensory block: $5.2 \pm 1.1 \mathrm{~cm}$, vs. olfaction block, $p=0.007$; vs. lateral line block, $p=$ 0.006; Fig. 4).

In the control blacktip sharks, capture occurred at $74.7 \pm 5.5 \mathrm{~ms}$, as the jaws began to close. Capture occurred significantly later when olfaction was blocked $(115.0 \pm 8.3 \mathrm{~ms}, p=$ 0.03). The time to capture did not vary significantly among any of the other treatments (Fig. 1). The earth-bound velocity of the prey as it entered the mouth of the predator did not vary significantly among any of the treatments. The earth-bound velocity of the predator during capture, however, was higher when the lateral line system was blocked, compared with when olfaction, vision, or the lateral line + vision were blocked (lateral line block: $3.4 \pm 0.9 \mathrm{BL} / \mathrm{s}$, olfactory block: $1.4 \pm 0.1 \mathrm{BL} / \mathrm{s}, p=0.02$; vision block: $1.2 \pm 0.2 \mathrm{BL} / \mathrm{s}, p=0.004$; lateral line + olfaction block: $1.1 \pm 0.2 \mathrm{BL} / \mathrm{s}, p<0.001)$.

In the control bonnetheads, the RSI value was $0.6 \pm 0.0$, indicating predominantly ram capture. The RSI values were not significantly different among any of the treatments (Fig. 3). Similarly, the ram distance and suction distance were not significantly different among any of 
the treatments (Fig. 4), nor were the velocity of the predator or the prey. In the control bonnetheads, capture occurred at $149.6 \pm 6.5 \mathrm{~ms}$, while the jaws were closing. When the lateral line + olfactory systems were blocked, the time to capture was significantly longer, $268.4 \pm 39.7$ ms $(p<0.001)$. When olfaction alone was blocked, time to capture was significantly longer $(184.0 \pm 15.3 \mathrm{~ms})$ compared with when the lateral line system was blocked (lateral line block: $123.1 \pm 13.9 \mathrm{~ms}, p=0.003)$, but was not significantly different from the control treatment. When either olfaction alone or the lateral line + olfaction were blocked, capture occurred as the jaws were closing and being retracted (Fig. 1). The time to capture was not significantly different among the other treatments.

In the control nurse sharks, the RSI value was $-0.5 \pm 0.1$, indicative of predominantly suction capture. When vision was blocked, the RSI value was significantly lower, $-0.8 \pm 0.1(p=$ 0.005), indicating that the blind nurse sharks were using more suction (Fig. 3). The ram distance was significantly smaller when vision was blocked $(0.5 \pm 0.2 \mathrm{~cm})$, compared with the control treatment $(p=0.01)$, and when the lateral line $(p<0.001)$ or electrosensory $(p<0.001)$ systems were blocked. The suction distance was also significantly larger when vision was blocked, $4.4 \pm$ $0.6 \mathrm{~cm}$, compared with when the lateral line $(p=0.01)$, lateral line + vision $(p=0.01)$, or electrosensory $(p=0.02)$ system was blocked, but was not significantly different from the control treatment (Fig. 4). There were no significant differences in RSI, ram distance, or suction distance among any of the other treatments. In the control nurse sharks, capture occurred at 50.7 $\pm 8.6 \mathrm{~ms}$, as the jaws reached peak gape. The time to capture did not vary significantly among any of the treatments (Fig. 1). The velocity of the prey as it entered the nurse sharks' mouth was not significantly different among any of the treatments. The velocity of the predator was significantly lower in the vision-blocked animals (control: $0.3 \pm 0.1 \mathrm{BL} / \mathrm{s}$, vision blocked: $0.1 \pm$ 
$0.1 \mathrm{BL} / \mathrm{s}, p=0.03)$. The control nurse sharks were typically moving slowly, but opened the mouth rapidly to draw in the prey in a suction event, engulfing it whole.

\section{Discussion}

\subsection{Modulation in response to sensory deprivation}

Successful prey capture in fishes depends in part on the ability to modulate, or systematically adapt feeding behaviors to differences in prey features such as size, shape, texture, location, or elusivity by transitioning between discrete behaviors within the animal's behavioral repertoire. Interspecific variation in modulatory capability is considered to be of central importance to the adaptation of an organism to its ecological niche (Liem, 1980) as it is generally considered to broaden the spectrum of prey that can be successfully consumed (Liem, 1978; Nemeth, 1997a, b). The ability to modulate prey capture in response to changes in the available sensory information may also broaden the environments in which a predator can successfully capture prey. Animals may face losses of sensory information due to natural environmental variation as well as changes resulting from human disturbances. Visual cues may be reduced or absent on a dark, moonless night, during periods of heavy cloud cover (McMahon and Holanov, 1995), or in very turbid environments (Vogel and Beauchamp, 1999). Olfactory receptors can be damaged by exposure to petroleum oil (Tierney et al., 2010), pesticides (Tierney et al., 2008; Tierney et al., 2007), detergents (Bardach et al., 1965), or the byproducts of eutrophication (Fisher et al., 2006; Yang et al., 2002), and olfactory-mediated behaviors can be disrupted by changes in pH (Dixson et al., 2014). The lateral line system can be damaged by aminoglycoside antibiotics (Kroese and van den Bercken, 1982; Owens et al., 2009) or heavy metals (Baker and Montgomery, 2001; Faucher et al., 2006; Faucher et al., 2008; Hernandez et al., 2006; Karlsen 
and Sand, 1987). The sensitivity and detection range of the electrosensory system is dramatically reduced in lower salinity water (McGowan and Kajiura, 2009); such salinity changes can occur following increases of freshwater inputs to coastal environments. Modulation when attempting to catch prey without the normal sensory cues may allow the animal to maintain success in acquiring prey (Gardiner and Motta, 2012). Lack of ability to modulate could result in lower fitness due to failure to procure prey (Ferry-Graham, 1998a; Liem, 1980; Nemeth, 1997a, b).

Intact blacktip sharks normally use vision to strike at prey from a distance in order to achieve the high velocities necessary for ram capture (Gardiner et al., 2014). They begin capture from a close proximity, with the prey positioned more or less directly in front of the mouth. Similarly, as in other ram-feeding carcharhiniform sharks (Ferry-Graham, 1997; Frazzetta and Prange, 1987; Motta et al., 1997), capture begins with the head being raised while the lower jaw is simultaneously depressed; prey is engulfed while the jaws are at their peak gape, and upper jaw protrusion begins as the lower jaw is being elevated, reaching its maximum just before the jaws close on the prey. When visual cues are absent, blacktip sharks can strike from close proximity using lateral line cues (Gardiner et al., 2014). Capture is initiated from less precise angles, so the blacktip shark modulates the capture sequence by elevating the head earlier and to a greater angle, to increase the probability that they engulf the prey. It captures the prey using less ram, which may delay the escape response of elusive prey, as the bow wave that alerts the prey to the approach of the predator would be smaller as it approaches at a lower velocity (FerryGraham et al., 2003; Viitasalo et al., 1998). The amount of suction remains unchanged and although the RSI value is lower, the blacktip shark remains a ram feeder.

When lateral line information is absent, blacktip sharks strike with higher velocity and fail to brake just prior to capture (Gardiner et al., 2014). This would leave less time to adjust 
their position prior to beginning capture, resulting in less precise capture angles. Capture in this case occurs with increased ram. When olfactory information is absent, blacktip sharks open the jaws more slowly. They may be less motivated when there are no food odor cues, as a similar behavior occurs with satiation in largemouth bass (Sass and Motta, 2002). They then begin to protrude the upper jaw later to coincide with the later peak gape and the start of lower jaw elevation, as protrusion assists in jaw closure (Frazzetta and Prange, 1987) by speeding up the closing of the mouth (Motta, 2004; Wilga et al., 2001). Prey is therefore engulfed later. Blacktip sharks hunting in environments contaminated with olfactory toxicants would be expected to open the jaws more slowly, which may allow the prey to escape; highly elusive prey such as teleost fish can initiate rapid escape responses in as little as $10 \mathrm{~ms}$ (Eaton et al., 1981). When the electrosensory cues are absent, blacktip sharks must make physical contact with the prey to initiate a successful capture (Gardiner et al., 2014). Capture is initiated from a greater angle and from a closer proximity, though not zero distance, as the prey typically made contact with the snout, rather than the mouth. This is likely an artifact due to the closer proximity of the prey at capture. If a shark aligns the capture angle at a given distance and continues along that trajectory, but fails to move the jaws until it is at a closer proximity to the prey, the capture angle will increase as the distance between the shark and the prey decreases (Fig. 5). Ram distance is smaller, also as a result of the shorter predator-prey distance at the start of capture, but the ram velocity is not changed. This suggests that modulation is not occurring, but rather a typical ram capture is simply being initiated from closer proximity as the animals use tactile cues to initiate jaw depression when electrical cues are absent (Gardiner et al., 2014).

Bonnetheads often feed on benthic crustaceans by scooping them up with their lower jaw. As such, their mouth remains open relatively long (Cortés et al., 1996; Wilga and Motta, 2000). 
Bonnetheads do not open the mouth and fail to capture prey when the electrosensory system is blocked (Gardiner et al., 2014). Otherwise, under these experimental conditions, the bonnetheads demonstrated little to no modulation in response to sensory deprivation. These sharks strike visually from a distance and cannot align a strike with prey in the water column when visual cues are absent (Gardiner et al., 2014). Capture begins at a close proximity with the prey more or less directly in front of the mouth, regardless of the available sensory information. Cranial elevation and depression, which are slight and temporally variable (Wilga and Motta, 2000), were not assessed, and the kinematic pattern in our study closely matched previous descriptions (Wilga and Motta, 2000). Capture begins with lower jaw depression, peak gape is briefly maintained, the lower jaw is elevated, and the upper jaw protruded. Prey capture occurs as the jaws are closing and the prey is primarily caught in the teeth. Upper jaw retraction occurs well after the jaws have closed. Total bite time was the longest of the three species at $220 \mathrm{~ms}$. The only significant changes observed were when olfactory information was absent, with bonnetheads engulfing the prey later in the capture sequence. The slower kinematics could allow elusive crustaceans to escape, but it also may give a little extra time to overcome such prey escape attempts. Due to their cephalofoil all hammerheads show greater maneuverability (increased lateral flexure and tighter turning ability) than carcharhinids (Kajiura et al., 2003). However, their typical decapod crustacean prey is most likely less elusive than bony fishes and the delay connected with the absence of odor information might not significantly affect feeding performance. Other sensory blocks did not significantly affect capture kinematics, therefore little kinematic modulation occurs in response to sensory deprivation in the bonnethead, consistent with their lack of modulation in response to differences in prey type or hardness (Wilga and Motta, 2000). This 
suggests that the ram-feeding behavior of the bonnethead is highly stereotyped under these experimental conditions.

Nurse sharks can use vision, the lateral line or electroreception to strike slowly from close proximity, generally by raising the head (Gardiner et al., 2014). Since suction is effective over only a distance of less than one mouth width, suction feeding varies over a smaller distance than ram feeding (Day et al., 2005; Ferry-Graham et al., 2001a; Ferry-Graham et al., 2003; Motta et al., 2008). This may explain the lack of variation in capture angle or capture distance among the treatments. Intact nurse sharks follow the kinematic pattern previously described for this species ((Matott et al., 2005; Motta et al., 2002; Motta et al., 2008): capture begins with lower jaw depression, followed shortly thereafter by labial cartilage extension. Maximum labial cartilage extension occurs slightly after peak gape. Lower jaw elevation then begins, followed shortly thereafter by labial cartilage retraction, and prey is engulfed while the jaws are at their maximum gape and the labial cartilages maximally extended. Though they do not appear to modulate in response to differences in prey size, type, or location ((Matott et al., 2005; Motta et al., 2002; Motta et al., 2008; Robinson and Motta, 2002), nurse sharks demonstrate considerable modulatory abilities with sensory impairment. When visual information is absent, nurse sharks decrease the amount of ram used, while increasing the amount of suction. The predator velocity during capture is also slower, but the prey velocity is unchanged, indicating that the blind nurse sharks are drawing the prey in over a greater distance, but at the same velocity, compared to when visual cues are available. Since the suction pressure generated relates to the rate of buccopharyngeal expansion (Day et al., 2005; Motta et al., 2008; Sanford and Wainwright, 2002; Svanback et al., 2002), it is likely that the blind nurse sharks are opening the jaws more rapidly than when visual cues are available, but these differences were not detected by the sample size of 
this study. This species has been described as a nocturnal feeder and has been observed sucking prey from crevices in the reef (Motta et al., 2008). Opening the jaws more rapidly to generate more suction would to some degree counter the effect of uncertainty regarding the exact location of the invisible prey, as decreasing the ram and increasing the suction results in the ingestion of a rounder parcel of water (Higham et al., 2006; Lowry and Motta, 2008).

In summary, striking and capture behaviors in sharks require precisely coordinated movements of the body and the jaws to successfully acquire the prey. Species that differ in habitat use, feeding anatomy, and prey capture behavior respond differently to sensory deprivation. In response to olfaction deprivation, blacktip sharks open the jaws more slowly and both blacktip sharks and bonnetheads engulf the prey later. Nurse sharks, on the other hand, will not feed in the absence of olfactory cues. In response to lateral line deprivation, blacktip sharks strike with increased velocity and fail to brake just prior to capture, while in bonnetheads or nurse sharks, the striking and capture behaviors are unchanged. In the absence of electrosensory cues, both blacktip sharks and nurse sharks must make physical contact with the prey in order to initiate a successful capture, while bonnetheads are unable to correctly time their jaw movements and therefore fail to capture prey. In the blacktip shark, this results in capture being initiated from a closer proximity and from greater angles, while in the nurse shark, which like all suction feeders initiates capture from a close proximity, capture distance is unchanged. Blocking vision results in the greatest amount of modulation. Blacktip sharks respond to visual deprivation by initiating capture from a closer proximity to the prey and from greater angles and capture prey using decreased ram, nurse sharks both decrease ram and increase suction, while bonnetheads are unable to capture prey in the absence of visual cues. 


\subsection{Functional limitations of modulation}

A general assumption is that ram-feeding sharks will demonstrate greater modulatory abilities during feeding compared to the suction-feeding species (reviewed in Motta and Wilga, 2001). Our results supported this only to some extent. In response to sensory deprivation, the ram-feeding blacktip shark demonstrated the greatest amount of modulation, followed by the suction-feeding nurse shark. However, little modulation was found in the ram-biting bonnethead. Many species of bony fish are capable of dramatically modulating the kinematics of feeding, switching from ram to suction for elusive vs. non-elusive prey (Ferry-Graham et al., 2001b; Liem, 1978, 1980; Nemeth, 1997a, b; Van Wassenbergh and De Rechter, 2011), and when feeding visually versus in the dark (Gardiner and Motta, 2012). In contrast, most shark species do not modulate capture in response to differences in the size or type of the prey (Ajemian and Sanford, 2007; Ferry-Graham, 1997; Matott et al., 2005) or do so only slightly, without switching feeding modalities (i.e. from ram to suction, Ferry-Graham, 1998a; Wilga, 1997). Similarly, in response to sensory deprivation, the sharks in the present study appear to modulate only slightly and do not switch feeding modalities.

Many sharks may be limited in their ability to modulate, based on their anatomy. Bony fishes that can switch feeding modalities generally possess the characteristics of both ram and suction feeders, including a fusiform body, suited for ram feeding, and a laterally occluded mouth and protrusible jaws, suited for suction feeding ((Carroll et al., 2004; Holzman et al., 2008a; Holzman et al., 2008b; Nemeth, 1997a; Norton, 1991b, 1995; Norton and Brainerd, 1993; Wainwright et al., 2001). These bony fishes can therefore modulate by decreasing ram, as well as increasing suction (Gardiner and Motta, 2012; Nemeth, 1997b). In contrast, the blacktip shark possesses the characteristics of a ram-feeding elasmobranch, including a large gape, body form 
suited to rapid swimming, and relatively small labial cartilages ((Motta, 2004; Motta and Wilga, 2001). Since the small labial cartilages do not occlude the mouth laterally, any increase in suction the animal might attempt to generate would likely not be focused anteriorly (Day et al., 2005; Wilga et al., 2007). In species that possess a small mouth and large labial cartilages that aid in forming a more tubular mouth, such as the nurse or bamboo sharks, the increased suction would be directed in front of the mouth (Motta, 2004; Motta et al., 2008; Motta and Wilga, 2001; Nauwelaerts et al., 2008; Nauwelaerts et al., 2007). Thus, the blacktip shark is likely unable to increase the amount of suction and modulates instead by decreasing the amount of ram. Similarly, the bonnethead has a large mouth which lacks labial folds (Wilga and Motta, 2000) so it likely cannot effectively increase the suction generated. In the bonnethead, when striking and capture occur, these behaviors tend to proceed in a rather stereotyped sequence.

The nurse shark is morphologically suited for suction feeding with its small tubular mouth, hypertrophied jaw and hyoid adductors, large labial cartilages, and small teeth (Motta, 2004; Motta et al., 2008), and it remains a suction feeder regardless of sensory deprivation. Specialized suction feeders, such as the nurse shark, can only suck prey from a distance of a few centimeters (Lowry and Motta, 2007; Lowry and Motta, 2008; Motta et al., 2008; Wilga and Sanford, 2008), although this distance can be extended slightly by placing the mouth near the substrate (Nauwelaerts et al., 2007). Since the prey were suspended off the bottom in the present study, the larger suction distance observed in blind nurse sharks is likely nearing the functional limitations of suction feeding. This species has body shape characteristics that are suited to slow swimming, including a broad head, blunt snout, more anteriorly positioned pectoral fins, more posteriorly positioned dorsal fins, and a low heterocercal tail (Maia et al., 2012). These features are likely to limit the amount of ram it can generate. 
These results suggest that in many elasmobranchs, capture plasticity is anatomically limited. Many carcharhinid and lamnid sharks are likely limited in the amount of suction force that can be generated by the anatomy of the mouth, as most species possess large mouths and lack labial folds (Compagno, 1984a, b). Many benthic and demersal species may be anatomically limited in the generation of ram by the shape of their bodies and tails. Species with more intermediate body types and a mouth with larger labial folds, such as the spiny dogfish, Squalus acanthias and the leopard shark, Triakis semifasciata, have been found to employ a combination of ram and suction (Ferry-Graham, 1998a; Lowry et al., 2007; Wilga and Motta, 1998; Wilga et al., 2007). These species have been found to modulate capture kinematics in response to prey size (Ferry-Graham, 1998a; Wilga, 1997) and their capacity to modulate in response to sensory deprivation warrants further investigation. Collectively, these results demonstrate that there are interspecific differences in the plasticity of striking and capture behaviors in sharks and that modulatory capability cannot be predicted simply by feeding modality. Species that demonstrate greater plasticity in response to changes in available sensory information, such as blacktip and nurse sharks, may forage successfully in a greater variety of environments than species with more stereotyped capture sequences, such as the bonnethead.

\section{Acknowledgements}

We thank J. Morris for the assistance with the design, construction, and maintenance of the flume system, J. Morris, M. Smith, K. Mara and the staff of Mote Marine Laboratory's Center for Shark Research for assistance with animal collection, handling, and care, A. Stamper and L. Byrd for veterinary support, B. Turffs for assistance with data collection, R. Dryer and B. Leigh for assistance with video analysis, J. Rohr for assistance with statistical analysis, and $\mathrm{H}$. Luciano for technical support. This work was funded by a Lerner-Gray Grant for Marine 
Research, an American Elasmobranch Society Donald R. Nelson Behavior Research Award, and an American Society for Ichthyologists and Herpetologists Raney Fund Award to J.M.G., as well as a collaborative National Science Foundation grant (IOS-0843440 to J.A., IOS-0841478 to R.E.H., and IOS-081502 to P.J.M.) and support from the Porter Family Foundation. J.M.G. was supported by a University of South Florida Presidential Doctoral Fellowship.

\section{Appendix A. Supplementary data}

Supplementary data associated with this article can be found in the online version at doi: \#\#\#. 


\section{References}

Aerts, P., 1990. Variability of the fast suction feeding process in Astatotilapia elegans (Teleostei: Cichlidae): a hypothesis of peripheral feedback control. J. Zool., Lond. 220, 653-678.

Ajemian, M.J., Sanford, C.P., 2007. Food capture kinematics in the deep-water chain catshark Scyliorhinus retifer. J. Mar. Biol. Assoc. U.K. 87, 1277-1286.

Arnold, S.J., 1983. Morphology, performance and fitness. Am. Zool. 23, 347-361.

Baker, C.F., Montgomery, J.C., 2001. Sensory deficit induced by cadmium in banded kokopu, Galaxias fasciatus, juveniles. Environ. Biol. Fishes 62, 455-464.

Bardach, J.E., Fujiya, M., Holl, A., 1965. Detergents: effects on the chemical senses of the fish Ictalurus natalis (le Sueur). Science 148, 1605-1607.

Benjamini, Y., Hochberg, Y., 1995. Controlling the false discovery rate: a practical and powerful approach to multiple testing. J. R. Statist. Soc. B. 57, 289-300.

Bethea, D.M., Hale, L., Carlson, J.K., Cortes, E., Manire, C.A., Gelsleichter, J., 2007. Geographic and ontogenetic variation in the diet and daily ration of the bonnethead shark, Sphyrna tiburo, from the eastern Gulf of Mexico. Mar. Biol. 152, 1009-1020.

Carroll, A.M., Wainwright, P.C., Huskey, S.H., Collar, D.C., Turingan, R.G., 2004. Morphology predicts suction feeding performance in centrarchid fishes. J. Exp. Biol. 207, 3873-3881.

Castro, J.I., 1996. The biology of the blacktip shark, Carcharhinus limbatus, off the southeastern United States. Bull. Mar. Sci. 59, 508-522.

Castro, J.I., 2000. The biology of the nurse shark, Ginglymostoma cirratum, off the Florida east coast and the Bahama Islands. Environ. Biol. Fishes 58, 1-22.

Compagno, L.J.V., 1984a. FAO Species Catalogue. Sharks of the World. An Annotated and Illustrated Catalogue of Shark Species Known to Date. Part 1. Hexanchiformes to Lamniformes. FAO Fisheries Synopsis No. 125, vol. 4.

Compagno, L.J.V., 1984b. FAO Species Catalogue. Sharks of the World. An Annotated and Illustrated Catalogue of Shark Species Known to Date. Part 2. Carcharhiniformes. FAO Fisheries Synopsis No. 125, vol. 4.

Cortés, E., Manire, C.A., Hueter, R.E., 1996. Diet, feeding habits, and diel feeding chronology of the bonnethead shark, Sphyrna tiburo, in southwest Florida. Bull. Mar. Sci. 58, 353-367.

Day, S.W., Higham, T.E., Cheer, A.Y., Wainwright, P.C., 2005. Spatial and temporal flow patterns during suction feeding of bluegill sunfish (Lepomis macrochirus) by particle image velocimetry. J. Exp. Biol. 208, 2661-2671.

Dixson, D.L., Jennings, A.R., Atema, J., Munday, P.L., 2014. Odor tracking in sharks is reduced under future ocean acidification conditions. Global Change Biol. 21, 1454-1462.

Eaton, R.C., Lavender, W.A., Wieland, C.M., 1981. Identification of Mauthner-initiated response patterns in goldfish: evidence from simultaneous cinematography and electrophysiology. J. Comp. Physiol. A 144, 521-531.

Edmonds, M.A., Motta, P.J., Hueter, R.E., 2001. Prey capture kinematics of the horn shark, Heterodontus francisci. Environ. Biol. Fishes 62, 415-427.

Elshoud-Oldendave, M.J.W., Osse, J.W.M., 1976. Functional morphology of the mechanism in the ruff - Gymnocephalus cernua (L. 1758) - (Teleostei, Percidae). J. Morphol. 150, 339-422.

Faucher, K., Dutto, G., Covès, D., Aubert, A., Lagardère, J.P., 2006. No efficiency of the lateral system on nocturnal feeding in the European sea bass (Dicentrarchus labrax L.). Aquaculture 252, 462-475. 
Faucher, K., Fichet, D., Miramand, P., Lagardere, J.P., 2008. Impact of chronic cadmium exposure at environmental dose on escape behaviour in sea bass (Dicentrarchus labrax L.; Teleostei, Moronidae). Environ. Poll. 151, 148-157.

Ferry-Graham, L.A., 1997. Feeding kinematics of juvenile swellsharks, Cephaloscyllium ventriosum. J. Exp. Biol. 200, 1255-1269.

Ferry-Graham, L.A., 1998a. Effects of prey size and mobility on prey-capture kinematics in leopard sharks Triakis semifasciata. J. Exp. Biol. 201, 2433-2444.

Ferry-Graham, L.A., 1998b. Feeding kinematics of hatchling swellsharks, Cephaloscyllium ventriosum (Scyliorhinidae): the importance of predator size. Mar. Biol. 131, 703-718.

Ferry-Graham, L.A., Lauder, G.V., 2001. Aquatic prey capture in ray-finned fishes: a century of progress and new directions. J. Morphol. 248, 99-119.

Ferry-Graham, L.A., Wainwright, P.C., Bellwood, D.R., 2001a. Prey capture in long-jawed butterflyfishes (Chaetodontidae): the functional basis of novel feeding habits. J. Exp. Mar. Biol. Ecol. 256, 167-184.

Ferry-Graham, L.A., Wainwright, P.C., Westneat, M.W., Bellwood, D.R., 2001b. Modulation of prey capture kinematics in the cheeklined wrasse Oxycheilinus digrammus (Teleostei: Labridae). J. Exp. Zool. 290, 88-100.

Ferry-Graham, L.A., Wainwright, P.C., Lauder, G.V., 2003. Quantification of flow during suction feeding in bluegill sunfishes. Zoology 106, 159-168.

Fisher, H.S., Wong, B.M., Rosenthal, G.G., 2006. Alteration of the chemical environment disrupts communication in a freshwater fish. Proc. R. Soc. Lond. B 273, 1187-1193.

Fouts, W.R., Nelson, D.R., 1999. Prey capture by the Pacific angle shark, Squatina californica: visually mediated strikes and ambush-site characteristics. Copeia 1999, 304-312.

Frazzetta, T.H., Prange, C.D., 1987. Movements of cephalic components during feeding in some requiem sharks (Carcharhiniformes: Carcharhinidae). Copeia 197, 979-993.

Frost, B.J., Sanford, C.P.J., 1999. Kinematics of a novel feeding mechanism in the osteoglossomorph fish Chitala chitala: is there a prey-type effect? Zoology 102, 18-30.

Gardiner, J.M., Motta, P.J., 2012. Largemouth bass (Micropterus salmoides) switch feeding modalities in response to sensory deprivation. Zoology 115, 78-83.

Gardiner, J.M., Atema, J., Hueter, R.E., Motta, P.J., 2014. Multisensory integration and behavioral plasticity in sharks from different ecological niches. PLoS ONE 9, e93036.

Hernandez, P.P., Moreno, V., Olivari, F.A., Allende, M.L., 2006. Sub-lethal concentrations of waterborne copper are toxic to lateral line neuromasts in zebrafish (Danio rerio). Hear. Res. 213, 1-10.

Higham, T.E., Day, S.W., Wainwright, P.C., 2005. Sucking while swimming: evaluating the effects of ram speed on suction generation in bluegill sunfish Lepomis macrochirus using digital particle image velocimetry. J. Exp. Biol. 208, 2653-2660.

Higham, T.E., Day, S.W., Wainwright, P.C., 2006. Multidimensional analysis of suction feeding performance in fishes: fluid speed, acceleration, strike accuracy, and the ingested volume of water. J. Exp. Biol. 209, 2713-2725.

Holzman, R., Day, S.W., Mehta, R.S., Wainwright, P.C., 2008a. Integrating the determinants of suction feeding performance in centrarchid fishes. J. Exp. Biol. 211, 3296-3305.

Holzman, R., Day, S.W., Mehta, R.S., Wainwright, P.C., 2008b. Jaw protrusion enhances forces exerted on prey by suction feeding fishes. J. R. Soc. Interface 5, 1445-1457.

Hothorn, T., Bretz, F., Westfall, P., 2008. Simultaneous inference in general parametric models. Biometr. J. 50, 346-363. 
Kajiura, S.M., Forni, J.B., Summers, A.P., 2003. Maneuvering in juvenile carcharhinid and sphyrnid sharks: the role of the hammerhead shark cephalofoil. Zoology 106, 19-28.

Karlsen, H.E., Sand, O., 1987. Selective and reversible blocking of the lateral line in freshwater fish. J. Exp. Biol. 133, 249-262.

Kroese, A.B.A., van den Bercken, J., 1982. Effects of ototoxic antibiotics on sensory hair cell functioning. Hear. Res. 6, 183-197.

Lauder, G.V., 1981. Intraspecific functional repertoires in the feeding mechanism of the characoid fishes, Lebiasina, Hoplias, and Chalceus. Copeia 1981, 154-168.

Lauder, G.V., 1983. Neuromuscular patterns and the origin of trophic specialization in fishes. Science 219, 1235-1237.

Lauder, G.V., Clark, B.D., 1984. Water flow patterns during prey capture by teleost fishes. J. Exp. Biol. 113, 143-150.

Liem, K.F., 1978. Modulatory multiplicity in the functional repertoire of the feeding mechanism in cichlid fishes. J. Morphol. 158, 323-360.

Liem, K.F., 1979. Modulatory multiplicity in the feeding mechanism of the cichlids, as exemplified by the invertebrate pickers of Lake Tanganyika. J. Zool., Lond. 189, 93-125.

Liem, K.F., 1980. Adaptive significance of intra- and interspecific differences in the feeding repertoires of cichlid fishes. Am. Zool. 20, 295-314.

Lowry, D., Motta, P.J., 2007. Ontogeny of feeding and cranial morphology in the whitespotted bambooshark Chiloscyllium plagiosum. Mar. Biol. 151, 2013-2023.

Lowry, D., Motta, P.J., 2008. Relative importance of growth and behaviour to elasmobranch suction-feeding performance over early ontogeny. J. R. Soc. Interface 5, 641-652.

Lowry, D., Motta, P.J., Hueter, R.E., 2007. The ontogeny of feeding behavior and cranial morphology in the leopard shark Triakis semifasciata (Girard 1854): a longitudinal perspective. J. Exp. Mar. Biol. Ecol. 341, 153-167.

Maia, A.M.R., Wilga, C.A.D., Lauder, G.V., 2012. Biomechanics of locomotion in sharks, rays, and chimaeras. In: Carrier, J.C., Musick, J.A., Heithaus, M.R. (Eds.), Biology of Sharks and Their Relatives, vol. I, 2nd ed. CRC Press, Boca Raton, pp. 125-151.

Maie, T., Furtek, S., Schoenfuss, H.L., Blob, R.W., 2014. Feeding performance of the Hawaiian sleeper, Eleotris sandwicensis (Gobioidei: Eleotridae): correlations between predatory functional modulation and selection pressures on prey. Biol. J. Linn. Soc. 111, 359-374.

Matott, M.P., Motta, P.J., Hueter, R.E., 2005. Modulation in feeding kinematics and motor pattern of the nurse shark Ginglymostoma cirratum. Environ. Biol. Fishes 74, 163-174.

McGowan, D.W., Kajiura, S.M., 2009. Electroreception in the euryhaline stingray, Dasyatis sabina. J. Exp. Biol. 212, 1544-1552.

McMahon, T.E., Holanov, S.H., 1995. Foraging success of largemouth bass at different light intensities: implications for time and depth of feeding. J. Fish Biol. 46, 759-767.

Motta, P.J., 2004. Prey capture behavior and feeding mechanics of elasmobranchs. In: Carrier, J.C., Musick, J.A., Heithaus, M.R. (Eds.), Biology of Sharks and Their Relatives. CRC Press, Boca Raton, p. 165-202.

Motta, P.J., Huber, D.R., 2012. Prey capture behavior and feeding mechanics of elasmobranchs. In: Carrier, J.C., Musick, J.A., Heithaus, M.R. (Eds.), Biology of Sharks and Their Relatives, vol. I, 2nd ed. CRC Press, Boca Raton, pp. 153-209.

Motta, P.J., Wilga, C.D., 2001. Advances in the study of feeding behaviors, mechanisms, and mechanics of sharks. Environ. Biol. Fishes 60, 131-156. 
Motta, P.J., Tricas, T.C., Hueter, R.E., Summers, A.P., 1997. Feeding mechanism and functional morphology of the jaws of the lemon shark Negaprion brevirostris (Chondrichthyes, Carcharhinidae). J. Exp. Biol. 200, 2765-2780.

Motta, P.J., Hueter, R.E., Tricas, T.C., Summers, A.P., 2002. Kinematic analysis of suction feeding in the nurse shark Ginglymostoma cirratum (Orectolobiformes, Ginglymostomidae). Copeia 2002, 24-38.

Motta, P.J., Hueter, R.E., Tricas, T.C., Summers, A.P., Huber, D.R., Lowry, D., Mara, K.R., Matott, M.P., Whitenack, L.B., Wintzer, A.P., 2008. Functional morphology of the feeding apparatus, feeding constraint and suction performance in the nurse shark Ginglymostoma cirratum. J. Morphol. 269, 1041-1055.

Nauwelaerts, S., Wilga, C.D., Sanford, C.P., Lauder, G.V., 2007. Hydrodynamics of prey capture in sharks: effects of substrate. J. R. Soc. Interface 4, 341-345.

Nauwelaerts, S., Wilga, C.D., Lauder, G.V., Sanford, C.P., 2008. Fluid dynamics of feeding behavior in white spotted bamboo sharks. J. Exp. Biol. 211, 3095-3102.

Nemeth, D.H., 1997a. Modulation of attack behavior and its effect on feeding performance in a trophic generalist fish, Hexagrammos decagrammus. J. Exp. Biol. 200, 2155-2164.

Nemeth, D.H., 1997b. Modulation of buccal pressure during prey capture in Hexagrammos decagrammus (Teleostei: Hexagrammidae). J. Exp. Biol. 200, 2145-2154.

Norton, S.F., 1991a. Capture success and diet of cottid fishes: the role of predator morphology and attack kinematics. Ecology 72, 1807-1819.

Norton, S.F., 1991b. Habitat use and community structure in an assemblage of cottid fishes. Ecology 72, 2181-2192.

Norton, S.F., 1995. A functional approach to ecomorphological patterns of feeding in cottid fishes. Environ. Biol. Fishes 44, 61-78.

Norton, S.F., Brainerd, E.L., 1993. Convergence in the feeding mechanics of ecomorphologically similar species in the Centrarchidae and Cichlidae. J. Exp. Biol. 176, 11-29.

Nyberg, D.W., 1971. Prey capture in the largemouth bass. Am. Midl. Nat. 86, 128-144.

O'Neill, M.W., Gibb, A.C., 2014. Does feeding behavior facilitate trophic niche partitioning in two sympatric sucker species from the American southwest? Physiol. Biochem. Zool. 87, $65-76$.

Owens, K.N., Coffin, A.B., Hong, L.S., Bennett, K.O., Rubel, E.W., Raible, D.W., 2009. Response of mechanosensory hair cells of the zebrafish lateral line to aminoglycosides reveals distinct cell death pathways. Hear. Res. 253, 32-41.

Packard, G.C., Boardman, T.J., 1999. The use of percentages and size-specific indices to normalize physiological data for variation in body size: wasted time, wasted effort? Comp. Biochem. Physiol. A. Mol. Integr. Physiol. 122, 37-44.

Pinheiro, J., Bates, D., DebRoy, S., Sarkar, D., R Core Team, 2013. nlme: Linear and Nonlinear Mixed Effects Models, $\mathrm{R}$ package version 3.1-3.111. http://CRAN.Rproject.org/package=nlme.

Pretlow-Edmonds, M.A., 1999. Prey Capture Kinematics of the Horn Shark, Heterodontus francisci. Master's Thesis, University of South Florida, Tampa.

R Core Team, 2013. R: A Language and Environment for Statistical Computing. R Foundation for Statistical Computing, Vienna, Austria.

Robinson, M.P., Motta, P.J., 2002. Patterns of growth and the effects of scale on the feeding kinematics of the nurse shark (Ginglymostoma cirratum). J. Zool., Lond. 256, 449-462. 
Sanford, C.P., Wainwright, P.C., 2002. Use of sonomicrometry demonstrates the link between prey capture kinematics and suction pressure in largemouth bass. J. Exp. Biol. 205, 34453457.

Sass, G.G., Motta, P.J., 2002. The effects of satiation on strike mode and prey capture kinematics in largemouth bass, Micropterus salmoides. Environ. Biol. Fishes 65, 441-454.

Sokal, R.R., Rohlf, F.J., 1995. Biometry: The Principles and Practices of Statistics in Biological Research. W.H. Freeman and Co., New York.

Svanback, R., Wainwright, P.C., Ferry-Graham, L.A., 2002. Linking cranial kinematics, buccal pressure, and suction feeding performance in largemouth bass. Physiol. Biochem. Zool. $75,532-543$.

Tierney, K.B., Singh, C.R., Ross, P.S., Kennedy, C.J., 2007. Relating olfactory neurotoxicity to altered olfactory-mediated behaviors in rainbow trout exposed to three currently-used pesticides. Aquat. Toxicol. 81, 55-64.

Tierney, K.B., Sampson, J.L., Ross, P.S., Sekela, M.A., Kennedy, C.J., 2008. Salmon olfaction is impaired by an environmentally realistic pesticide mixture. Environ. Sci. Technol. 42, 4996-5001.

Tierney, K.B., Baldwin, D.H., Hara, T.J., Ross, P.S., Scholz, N.L., Kennedy, C.J., 2010. Olfactory toxicity in fishes. Aquat. Toxicol. 96, 2-26.

Van Wassenbergh, S., De Rechter, D., 2011. Piscivorous cyprinid fish modulates suction feeding kinematics to capture elusive prey. Zoology 114, 46-52.

Van Wassenbergh, S., Herrel, A., Adriaens, D., Aerts, P., 2006. Modulation and variability of prey capture kinematics in clariid catfishes. J. Exp. Zool. 305A, 559-569.

Viitasalo, M., Kiørboe, T., Flinkman, J., Pedersen, L.W., Visser, A.W., 1998. Predation vulnerability of planktonic copepods: consequences of predator foraging strategies and prey sensory abilities. Mar. Ecol. Prog. Ser. 175, 129-142.

Vogel, J.L., Beauchamp, D.A., 1999. Effects of light, prey size, and turbidity on reaction distances of lake trout (Salvelinus namaycush) to salmonid prey. Can. J. Fish. Aqua. Sci. 56, 1293-1297.

Wainwright, P.C., 1988. Morphology and ecology: functional basis of feeding constraints in Caribbean labrid fishes. Ecology 69, 635-645.

Wainwright, P.C., Lauder, G.V., 1986. Feeding biology of sunfishes: patterns of variation in the feeding mechanism. Zool. J. Linn. Soc. 88, 217-228.

Wainwright, P.C., Ferry-Graham, L.A., Waltzek, T.B., Carroll, A.M., Hulsey, C.D., Grubich, J.R., 2001. Evaluating the use of ram and suction during prey capture by cichlid fishes. J. Exp. Biol. 204, 3039-3051.

Weihs, D., 1980. Hydrodynamics of suction feeding of fish in motion. J. Fish Biol. 16, 425-433.

Wilga, C.D., 1997. Evolution of Feeding Mechanisms in Elasmobranchs: A Functional Morphological Approach. Ph.D. Thesis, University of South Florida, Tampa.

Wilga, C.D., Motta, P.J., 1998. Conservation and variation in the feeding mechanism of the spiny dogfish Squalus acanthias. J. Exp. Biol. 201, 1345-1358.

Wilga, C.D., Motta, P.J., 2000. Durophagy in sharks: feeding mechanics of the hammerhead Sphyrna tiburo. J. Exp. Biol. 203, 2781-2796.

Wilga, C.D., Sanford, C.P., 2008. Suction generation in white-spotted bamboo sharks Chiloscyllium plagiosum. J. Exp. Biol. 211, 3128-3138.

Wilga, C.D., Hueter, R.E., Wainwright, P.C., Motta, P.J., 2001. Evolution of upper jaw protrusion mechanisms in elasmobranchs. Am. Zool. 41, 1248-1257. 
Wilga, C.D., Motta, P.J., Sanford, C.P., 2007. Evolution and ecology of feeding in elasmobranchs. Integr. Comp. Biol. 47, 55-69.

Wu, E.H., 1993. The Functional Morphology of Feeding Mechanisms in Orectolobiform Sharks. Ph.D. Thesis, Harvard University, Cambridge.

Yang, M.L., Huang, T.S., Lee, Y.S., Chen, T.H., Chen, S.Y., Lu, F.J., 2002. Inhibition of endogenous thyroid hormone receptor-beta and peroxisone proliferator-activated receptor-alpha activities by humic acid in a human-derived liver cell line. Thyroid 12, $361-371$. 


\section{Figure Legends}

Fig. 1. Onset and duration in milliseconds (ms) are shown for each kinematic variable measured in three shark species (left to right): blacktip shark, Carcharhinus limbatus; bonnethead, Sphyrna tiburo; nurse shark, Ginglymostoma cirratum. Data are shown for animals with all senses intact (control) and following blocks of the sensory systems as indicated in the figure legend (LL: lateral line). Dotted lines indicate the timing of prey engulfment. Error bars are s.e.m. Red dotted lines and stars $(*$, to the left of a bar for onset time of a kinematic event, above a bar for duration) indicate significant differences from the control at $\alpha=0.05$; for comparisons among treatments, see Tables S1-S3 in the supplementary online Appendix. Blacktip shark and bonnethead illustrations from Diane Rome Peebles, with permission. Nurse shark illustration from José Castro, with permission.

Fig. 2. Plots of the gape cycle for representative prey capture events (individual traces that most closely matched the means) for three species of sharks (top to bottom): blacktip shark, Carcharhinus limbatus; bonnethead, Sphyrna tiburo; nurse shark, Ginglymostoma cirratum. Data are shown for animals with all senses intact (control) and after blocks of the sensory systems as indicated. For details of statistical analyses, see Tables S1-S3 in the supplementary online Appendix. Blacktip shark and bonnethead illustrations from Diane Rome Peebles, with permission. Nurse shark illustration from José Castro, with permission.

Fig. 3. Boxplots of the ram-suction index (RSI) values for the three shark species (left to right): blacktip shark, Carcharhinus limbatus; bonnethead, Sphyrna tiburo; nurse shark, Ginglymostoma cirratum. Data are shown for animals with all senses intact (control) and following blocks of the 
sensory systems as indicated in the figure legend (LL: lateral line). Top and bottom whiskers represent maximum and minimum data points, respectively. RSI value may range from -1 (pure suction) to +1 (pure ram). $*$ denotes significant differences between pairs of treatments (indicated by the ends of the brackets) at $\alpha=0.05$. Blacktip shark and bonnethead illustrations from Diane Rome Peebles, with permission. Nurse shark illustration from José Castro, with permission.

Fig. 4. Distances moved by the predator (dark gray) and prey (light gray) during capture for the three species (top to bottom): blacktip shark, Carcharhinus limbatus; bonnethead, Sphyrna tiburo; nurse shark, Ginglymostoma cirratum, with all senses intact (control) and following blocks of the sensory systems as indicated in the figure legend (LL: lateral line). The total length of the bars (light gray + dark gray) is centered on the $0 \mathrm{~cm}$ line to allow for comparisons of the proportion of the distance travelled by predator (i.e. ram) vs. prey (i.e. due to predator suction). The $0 \mathrm{~cm}$ line represents equal distances travelled by predator and prey. Error bars are s.e.m. * denotes significant differences between pairs of treatments (indicated by the ends of the brackets) at $\alpha=0.05$. Blacktip shark, bonnethead, shrimp and pinfish illustrations from Diane Rome Peebles, with permission. Nurse shark illustration from José Castro, with permission.

Fig. 5. Illustration of the change in capture angle, $\theta$, that would be expected to occur if an animal were to align the capture angle at a particular position $\left(\mathrm{P}_{1}\right)$ and distance from the prey (dotted line), but then fail to initiate capture until it was closer to the prey $\left(\mathrm{P}_{2}\right)$. If the animal continues along the same heading (solid line with arrow), the capture angle from its new position $\left(\mathrm{P}_{2}\right)$ will be greater $\left(\theta_{2}>\theta_{1}\right)$. Diagram is for illustrative purposes only; predator-prey distances, capture 
angles, and size of the predator and the prey are not representative. Blacktip shark illustration from Diane Rome Peebles, with permission. 

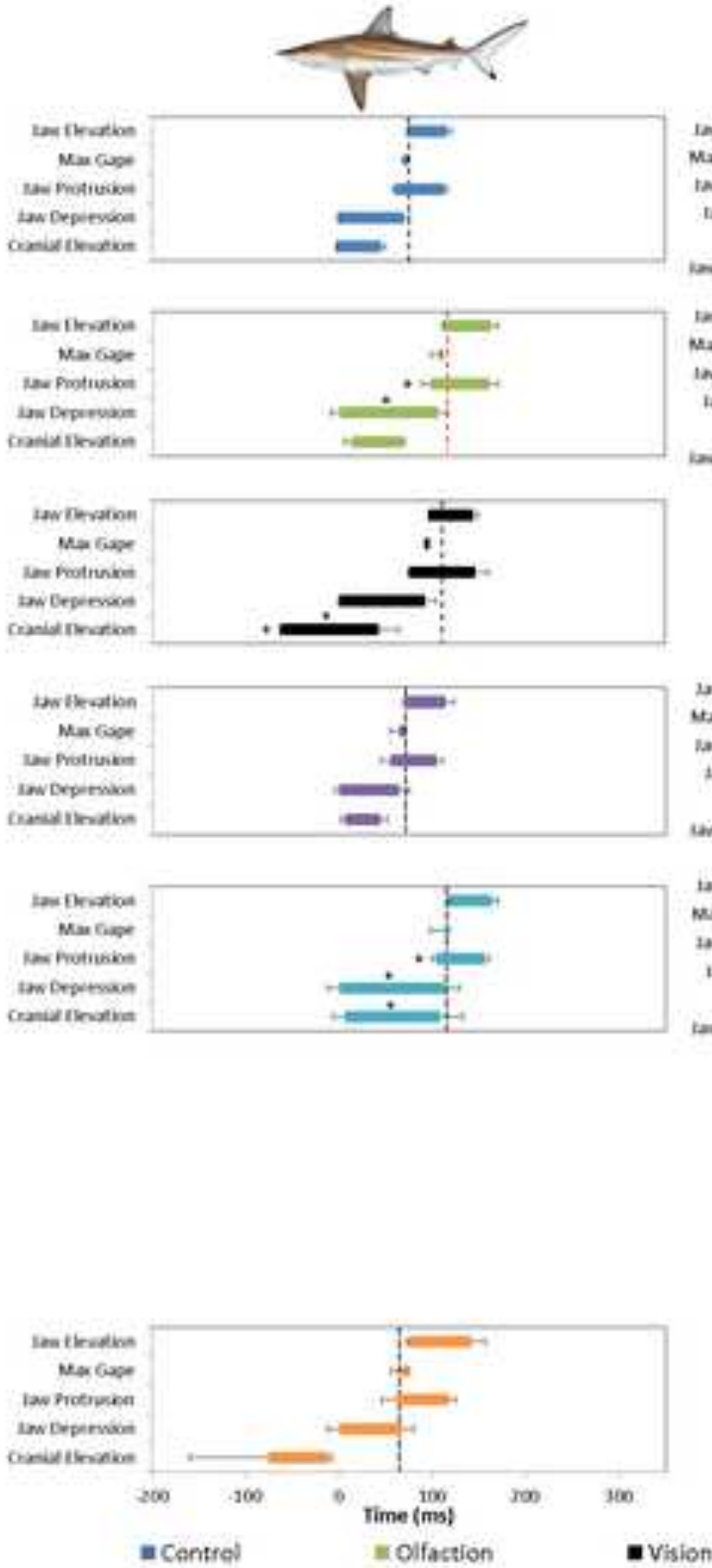
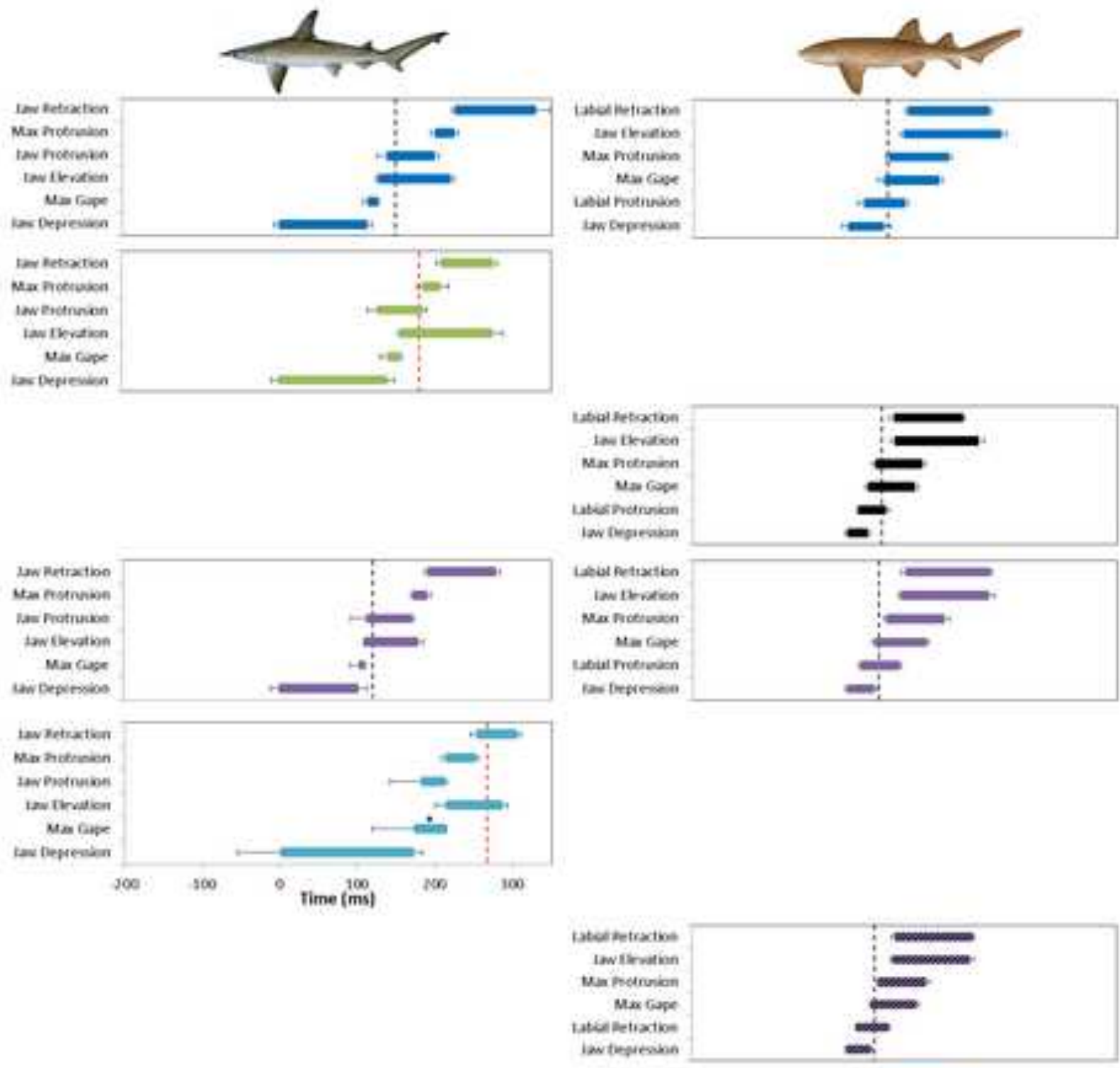

iantesciembia

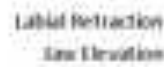

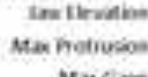

Mas cise

4 Libat notruicon

is Deprenise

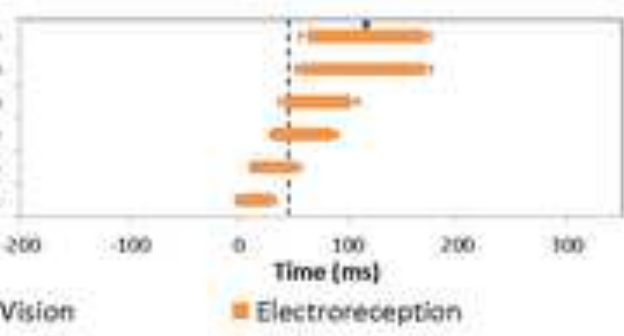



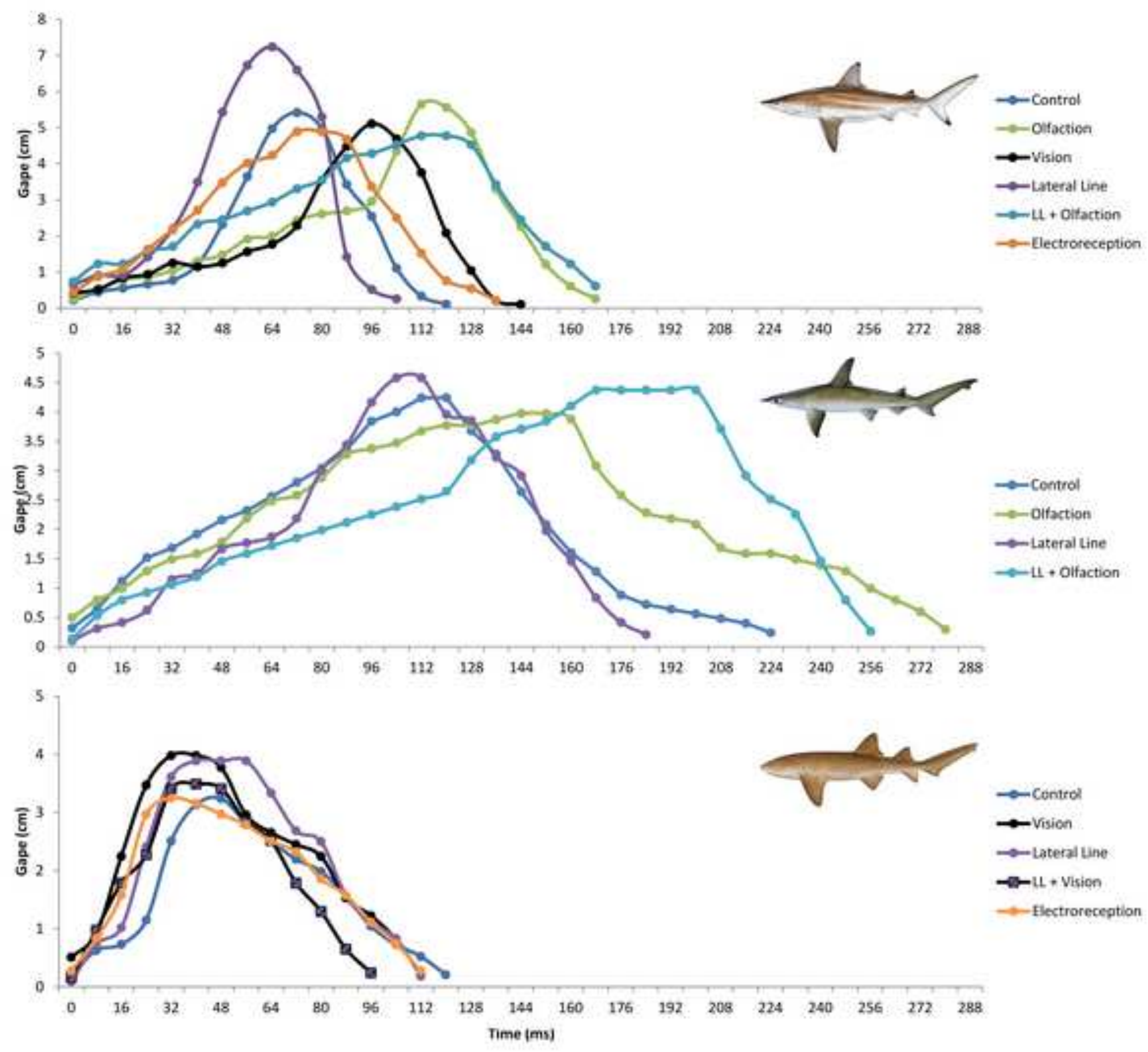


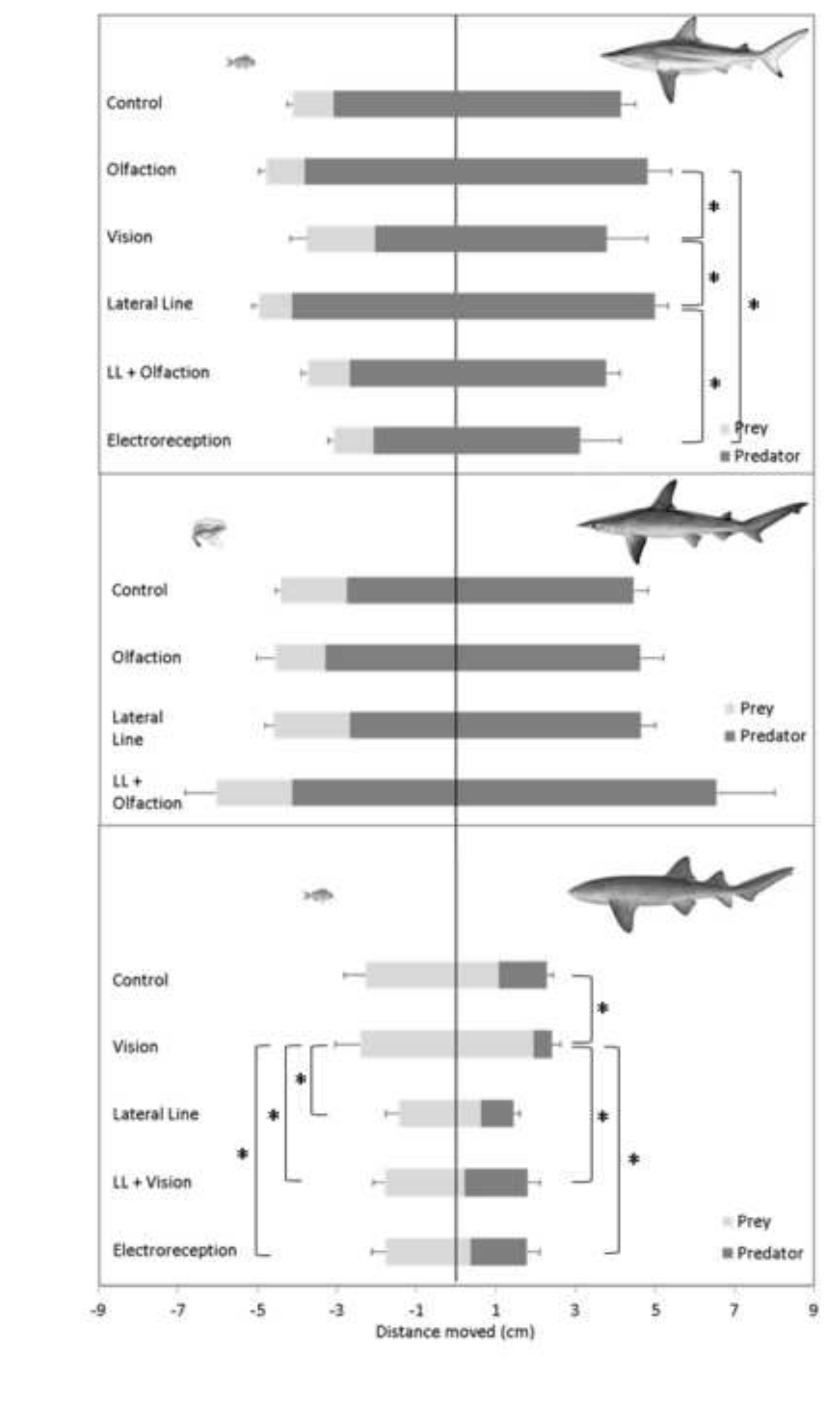

Figure 4 4

(2n)

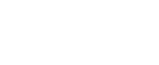

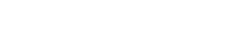
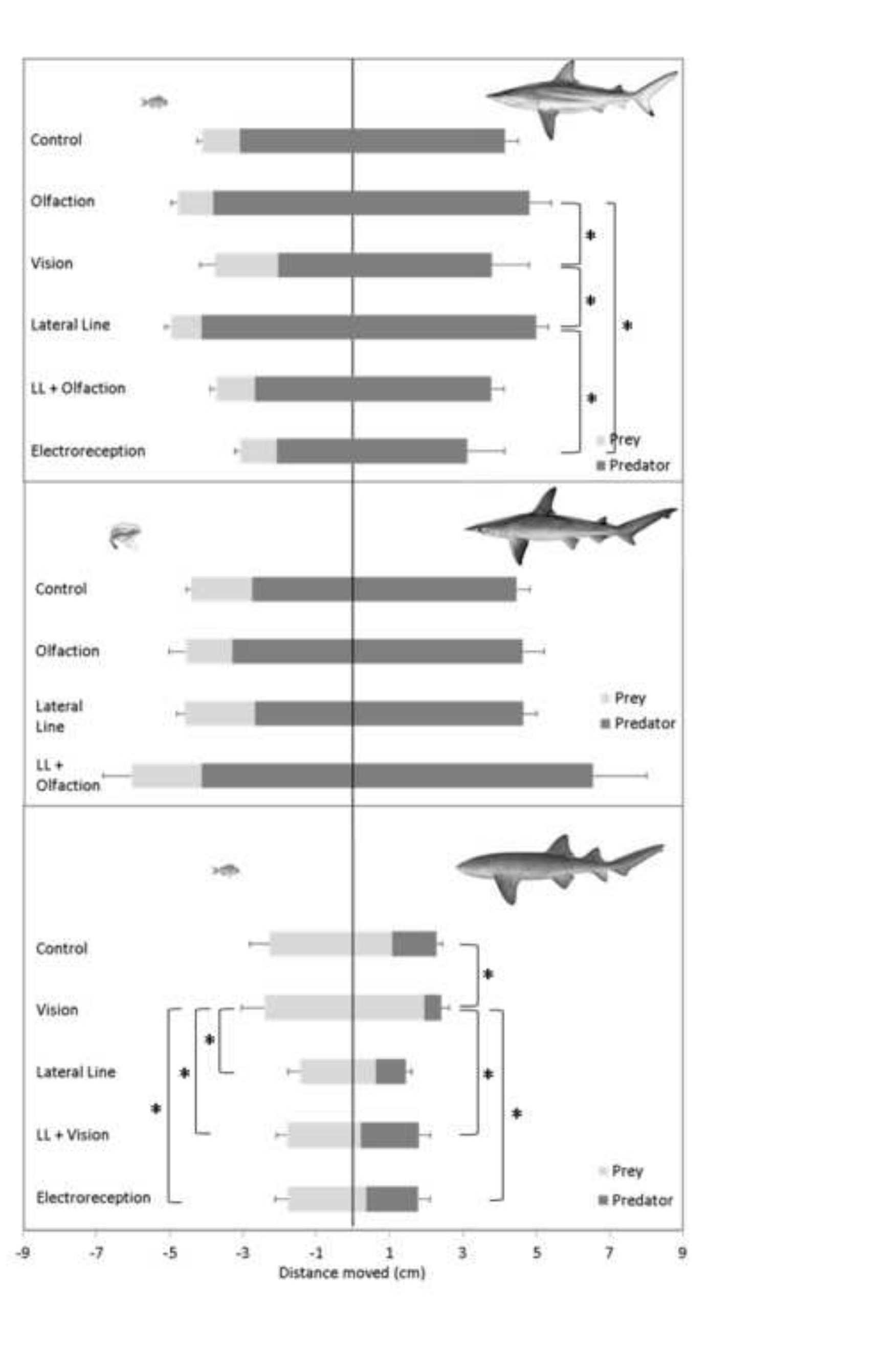

(n)




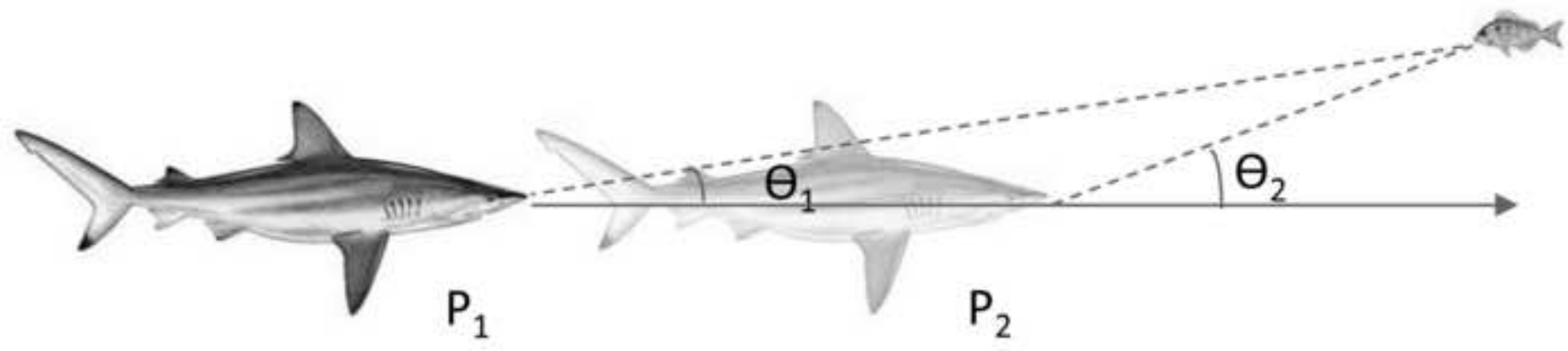

